\title{
Effects of three different conjugated linoleic acid preparations on insulin signalling, fat oxidation and mitochondrial function in rats fed a high-fat diet
}

\author{
Joo Sun Choi, In-Uk Koh, Myeong Ho Jung and Jihyun Song* \\ Division of Metabolic Diseases, Center for Biomedical Sciences, National Institute of Health, 194 Tongillo, Eunpyeong-gu, \\ Seoul, 122-701, Korea
}

(Received 4 July 2006 - Revised 8 January 2007 - Accepted 31 January 2007)

\begin{abstract}
To investigate the effects of three different conjugated linoleic acid (CLA) preparations containing different ratios of CLA isomers on insulin signalling, fatty acid oxidation and mitochondrial function, Sprague-Dawley rats were fed a high-fat diet either unsupplemented or supplemented with one of three CLA preparations at $1 \%$ of the diet for 8 weeks. The first CLA preparation contained approximately $30 \%$ cis- 9 , trans- 11 $(c 9, t 11)$-CLA isomer and $40 \%$ trans-10, cis-12 ( $t 10, c 12)$-CLA isomer (CLA-mix). The other two preparations were an 80:20 mix $(c 9, t 11$ CLA-mix) or a 10:90 mix of two CLA isomers $(t 10, c 12$-CLA-mix). Insulin resistance was decreased in all three supplemented groups based on the results of homeostasis model assessment and the revised quantitative insulin-sensitivity check index. The phosphorylation of insulin receptor substrate-1 on serine decreased in the livers of all three supplemented groups, while subsequent Akt phosphorylation increased only in the $t 10, c 12$-CLA-mix group. Both the $c 9, t 11$-CLA-mix and the $t 10, c 12$-CLA-mix increased the expression of hepatic adiponectin receptors R1 and 2 , which are thought to enhance insulin sensitivity and fat oxidation. The $c 9, t 11$-CLA-mix increased protein and mRNA levels of PPAR $\alpha$, acyl-CoA oxidase and uncoupling protein, which are involved in fatty acid oxidation and energy dissipation. The $c 9, t 11-C L A-m i x$ enhanced mitochondrial function and protection against oxidative stress by increasing the activities of cytochrome $c$ oxidase, manganese-superoxide dismutase, glutathione peroxidase, and glutathione reductase and the level of GSH. In conclusion, all three CLA preparations reduced insulin resistance. Among them, the $c 9, t 11$-CLA-mix was the most effective based on the parameters reflecting insulin resistance and fat oxidation, and mitochondrial antioxidative enzyme activity in the liver.
\end{abstract}

Conjugated linoleic acid: Insulin resistance: Mitochondrial function

The prevalence of obesity, metabolic syndrome and type 2 diabetes mellitus is increasing throughout the world (Ford, 2004; Grundy, 2004). There is increasing interest in dietary supplementation with conjugated linoleic acid (CLA), because it prevents obesity and improves insulin resistance (Tsuboyama-Kasaoka et al. 2000; Plum et al. 2002; Larsen et al. 2003; Rainer \& Heiss, 2004). CLA is a group of positional and geometric conjugated dienoic isomers of linoleic acid $(18: 2 n-6)$ that are present in dairy products and meat (Wang \& Jones, 2004). Although the cis-9, trans-11 $(c 9, t 11)$-CLA isomer is the principal dietary form of CLA, commercial CLA supplements usually contain large quantities of the trans-10, cis-12 (t10,c12)-CLA isomer (Wang \& Jones, 2004).

The results of studies in which rodents were fed various ratios of $c 9, t 11$-CLA and $t 10, c 12$-CLA isomers indicate that $t 10, c 12$-CLA has a greater effect on weight gain and fat deposition than $c 9, t 11$-CLA does (Tsuboyama-Kasaoka et al. 2000; Nagao et al. 2003b). Some human studies have shown that both CLA isomers do not improve insulin sensitivity in obese men with the metabolic syndrome and diabetic patients (Riserus et al. 2002; Moloney et al. 2004). In contrast, a mixture of CLA improved insulin sensitivity in young, sedentary subjects (Eyjolfson et al. 2004). Although human consumption of $t 10, c 12$-CLA is not advocated because of the possibility of insulin resistance, this adverse effect was not observed when CLA was included in diets containing high levels of fat (Ryder et al. 2001; Ealey et al. 2002). More studies are required to fully understand the mechanisms involved in the beneficial or deleterious effects of CLA isomers on insulin resistance.

Studies using normal rats and diets with 30-40\% energy from fat, which mimic the meal patterns of individuals in developed countries, have given much information to further understand the mechanisms by which high-fat (HF) feeding induces insulin resistance, and to develop preventive measures. Consumption of diets high in fat reduces the expression of insulin receptor substrate (IRS), activity of phosphatidyl inositol (PI) 3-kinase, and phosphorylation of Akt in the liver (Shulman, 2000; Lowell \& Shulman, 2005).

\footnotetext{
Abbreviations: AdipoR, adiponectin receptor; $c 9, t 11$, cis-9, trans-11; CLA, conjugated linoleic acid; COX, cytochrome $c$ oxidase; GPx, glutathione peroxidase; GR, glutathione reductase; HF, high-fat; HOMA, homeostasis model assessment; IRS, insulin receptor substrate; PI, phosphatidyl inositol; ROS, reactive oxygen species; R-QUICKI, revised quantitative insulin-sensitivity check index; SDH, succinate dehydrogenase; t10,c12, trans-10, cis-12; UCP, uncoupling protein.

* Corresponding author: Dr Jihyun Song, fax +82 2354 1057, email jihyun_s@yahoo.com
} 
To investigate the effects of CLA on insulin resistance of rats fed diets with HF contents, it might be necessary to measure the expression or activation of molecules related to insulin signalling events.

Recently, it was suggested that receptor binding of adiponectin regulates insulin sensitivity (Yamauchi et al. 2003). Decreased expression of the adiponectin receptor (AdipoR) in insulin-resistant animals is correlated with decreased AMP kinase activation, $\operatorname{PPAR} \alpha$ activation, fatty acid oxidation and glucose uptake (You \& Crabb, 2004; Kadowaki $\&$ Yamaguchi, 2005). However, there are few studies on the effects of CLA on AdipoR expression and serum adiponectin concentrations. Impaired mitochondrial function by oxidative stress may play a role in the pathogenesis of insulin resistance and type 2 diabetes (Shulman, 2000). Because CLA decreases blood lipid concentrations and has antioxidant properties (Palacios et al. 2003; Su et al. 2003), it may protect mitochondria from oxidative stress, especially when insulin resistance is induced by diets with HF contents.

The objectives of the present study were to investigate the effects of an HF diet supplemented with CLA preparations on insulin resistance and fatty acid oxidation, and mitochondrial function in normal rats. We monitored proteins involved in energy metabolism, the antioxidant defence system and the respiratory chain complex in mitochondria to identify the mechanism by which CLA improves insulin resistance.

\section{Materials and methods}

\section{Animals and diets}

Male Sprague-Dawley rats were obtained from the Experimental Animal Resources Laboratories of the Korean Food and Drug Agency. They were housed in plastic cages in a room with a $12 \mathrm{~h}$ light $-12 \mathrm{~h}$ dark cycle and maintained at $22 \pm 1{ }^{\circ} \mathrm{C}$. After adaptation for 1 week, rats were randomly assigned to four groups of seven animals each.

For 8 weeks, the rats received either an unsupplemented HF diet or the HF diet supplemented with one of three CLA preparations. The HF diet contained $23 \%$ fat $(20.5 \%$ beef tallow and $2.5 \%$ maize oil), which accounted for about $45 \%$ of the energy content of the diet. The CLA diets contained about $1 \%$ of the respective CLA preparation, $19.5 \%$ beef tallow and $2.5 \%$ maize oil. Maize oil was included to provide essential fatty acids. The first CLA preparation, termed as CLAmix, consisted of $31.3 \% c 9, t 11$-CLA, $36.7 \% t 10, c 12-C L A$, $17.3 \%$ other isomers of CLA, and $14.8 \%$ of other fatty acids. Thus, the diet fed to the CLA-mix group contained a $30: 40$ mix of the $c 9, t 11-C L A$ isomer and $t 10, c 12-C L A$ isomer, an approximately equal ratio of the two major CLA isomers. The second CLA preparation, referred to as $c 9, t 11-$ CLA-mix, was an 80:20 mix of the two CLA isomers, and consisted of $76.5 \% \quad c 9, t 11-C L A, 17.2 \% \quad t 10, c 12-C L A$ and $6.3 \%$ other isomers of CLA ( $c 9, t 11-C L A-m i x$ group). The third CLA preparation, referred to as $t 10, c 12-C L A-m i x$, was a 10:90 mix of the two CLA isomers, and consisted of $89.6 \% t 10, c 12$-CLA and $10.4 \% c 9, t 11$-CLA ( $t 10, c 12-C L A-$ mix). Supplying the pure form of each isomer would enable us interpret the results much simpler than supplying CLA mixtures. However, we used the CLA mixtures for two reasons. One is that we expect the CLA mix, one of the CLA mixtures, to give the synergic effects by both major CLA isomers. The other reason is availability of CLA preparations. The pure form of $c 9, t 11$-CLA or $t 10, c 12-C L A$ cannot be easily obtained due to economical and technical reasons. Although we did not use pure forms of each isomer, the $c 9, t 11-C L A$ mix or $t 10, c 12-C L A$ mix may represent $c 9, t 11$-CLA and $t 10, c 12-$ CLA respectively since each preparation contains a high percentage of either $c 9, t 11$-CLA or $t 10, c 12$-CLA. All four diets also contained $23 \%$ casein, $40.7 \%$ sucrose, $3 \%$ Brewer's yeast, $4.8 \%$ celluose, $4 \%$ mineral mix, $1.2 \%$ vitamin mix and $0.3 \%$ methionine (Choi et al. 2004). Feed and water were available ad libitum throughout the experiment. Food intake was recorded at the same time each day and body weight was recorded weekly.

\section{Blood and tissue collection for biochemical analysis}

After 8 weeks, the rats were fasted overnight, anaesthetised, and blood was obtained by heart puncture. Serum was collected and stored at $-20^{\circ} \mathrm{C}$. Liver and leg skeletal muscle were collected, weighed, frozen in liquid $\mathrm{N}_{2}$ and stored at $-70^{\circ} \mathrm{C}$ until further processing. Mitochondrial and cytosolic fractions were prepared from liver and muscle by ultracentrifugation and stored at $-70^{\circ} \mathrm{C}$. Serum glucose concentrations were determined using an enzymic assay (Asan Pharmaceutical, Yongin, Gyeonggido, Korea). ELISA were used for measurement of serum insulin concentrations (Rat Insulin Kit RPN2567, Amersham, Bucks, UK) and adiponectin concentrations (Mouse/Rat Adiponectin ELISA Kit, K1002-1; B-Bridge International, Inc., Sunnyvale, CA, USA). Fasting serum insulin and glucose concentrations were used to calculate insulin resistance from the homeostasis model assessment (HOMA) for insulin resistance: insulin $(\mu \mathrm{U} / \mathrm{ml}) \times$ glucose concentration (mmol/l)/22.5 (Matthews et al. 1985). A high HOMA index denotes low insulin sensitivity, although it should be acknowledged that the HOMA model has not been validated for use in animal models (Wallace et al. 2004). To assess insulin sensitivity, another derived index of insulin resistance was suggested, i.e. the revised quantitative insulin sensitivity check index (R-QUICKI) $(1 / \log$ insulin $(\mu \mathrm{U} / \mathrm{ml})+$ log glucose $(\mathrm{mg} / \mathrm{dl})+\log$ NEFA $(\mathrm{mmol} / \mathrm{l}))$ (Perseghin et al. 2001; de Roos et al. 2005).

\section{Glucose metabolising enzyme activities and glycogen concentrations}

The activity of glucose-6-phosphatase was assayed according to a previously described method (Baginski et al. 1974) with a slight modification. After the reaction with glucose-6-phosphatase, the liberated inorganic phosphate in a sample of supernatant fraction was determined using a reaction based on the molybdenum blue method (Phosphor B-Test Wako; Wako Pure Chemical Industries Ltd, Osaka, Japan). The activity of phosphoenolpyruvate carboxykinase was measured as previously described (Chang \& Lane, 1966) with a slight modification. One unit phosphoenolpyruvate carboxykinase was defined as the enzyme activity resulting in the formation of $1 \mu \mathrm{mol} \mathrm{NAD}{ }^{+} / \mathrm{min}$ per mg protein. Hepatic glycogen content was analysed using a modification of a previously described method (Heidelberger et al. 1954). 
Activities of mitochondrial electron transport chain enzymes

We assessed mitochondrial function from the activities of succinate dehydrogenase (SDH) (complex II) and cytochrome $c$ oxidase (COX) (complex IV). SDH activity was measured by kinetic analysis (Owen \& Freer, 1970). The activity of SDH was estimated colorimetrically at $600 \mathrm{~nm}$ from reduction of 2,6-dichloroindolphenol during oxidation of succinate. Activity was expressed as $\mu \mathrm{mol}$ 2,6-dichloroindolphenol reduced/min per $\mathrm{mg}$ protein. The activity of COX was determined by a previously described method (Wharton \& Tzogaloff, 1967). One unit of enzyme activity was defined as that which resulted in the oxidation of $1 \mu \mathrm{mol}$ ferrocytochrome $c$ (the reduced form of cytochrome $c$ )/min per $\mathrm{mg}$ protein.

Activities of hepatic mitochondrial antioxidant enzymes and lipid peroxidation product

Activities of manganese-superoxide dismutase, glutathione peroxidase (GPx) and glutathione reductase (GR) and concentrations of GSH and malondialdehyde were measured using the following kits from Oxis Research (Portland, OR, USA): Bioxytech SOD-525, Bioxytech GPx-340, Bioxytech GR340, Bioxytech GSH-340, and Bioxytech MDA-586, respectively.

\section{Ribonucleic acid extraction and analysis of messenger} ribonucleic acid expression

Total RNA was extracted from tissues using TRI reagent (Molecular Research, Cincinnati, OH, USA) according to the manufacturer's instructions. RNA expression of uncoupling protein (UCP) 2, UCP3 and acyl-CoA oxidase was quantified by using specific primer sets and RT-PCR methods as described previously (Choi et al. 2004). Gel electrophoresis and ethidium bromide staining were used for quantification of PCR products. SDH and COXIII mRNA levels were quantified by real-time quantitative RT-PCR using SYBR green PCR reagents (Applied Biosystems, Foster City, CA, USA), and the ABI PRISM 7900 HT sequence-detection system (Applied Biosystems). The $C_{t}$ values obtained were the threshold cycles at which a statistically significant increase in SYBR green emission intensity occurred. Data are expressed as $2^{-\Delta \Delta \mathrm{C}_{\mathrm{T}}}$ values obtained by normalising to $18 \mathrm{~S}$ ribosomal RNA and then the mean $\Delta \mathrm{C}_{\mathrm{T}}$ values to the $\mathrm{HF}$ group. The PCR primers used were as follows: SDH, forward, 5'-GGAGGGGTCTCTCTTTTTGG-3', and reverse, 5'-GACAGGCCTTTCCCTAGGTC-3'; COXIII, forward, $5^{\prime}$-AAGGCCACCACACCCTATT-3', and reverse, 5'-AAATGCTCAGAAAAATCCGGC-3'; 18S rRNA, forward, 5'-GTCGTACCACTGGCATTGTG-3', and reverse, 5'-CTCTCAGCTGTGGTGGTGAA-3'.

\section{Immunoblot analysis}

Equal amounts of whole lysate protein were separated by 5$10 \%$ SDS-PAGE, transferred to polyvinylidene difluoride membranes, incubated in blocking buffer and treated with primary antibodies. Rabbit polyclonal antibodies against IRS-1, PPAR $\alpha, \operatorname{PPAR} \gamma, \operatorname{PPAR} \gamma$ coactivator $1 \alpha$ and actin were obtained from Santa Cruz Biotechnology Inc. (Santa Cruz,
CA, USA). Rabbit polyclonal antibodies against phosphoIRS-1-ser307, Akt, and phospho-Akt-ser473 were obtained from Cell Signaling Technology Inc. (Danvers, MA, USA). Rabbit polyclonal antibodies against AdipoR1 and AdipoR2 were purchased from $\alpha$-Diagnostic Inc. (San Antonio, TX, USA). Appropriate secondary antibodies were used, and the bands were visualised using ECL Western blotting detection reagents (RPN2106; Amersham, Bucks, UK) and X-ray film (AGFA, Mortsel, Belgium). Tina 2.0 software (Silk Scientific Inc., Orem, UT, USA) was used for densitometric analysis of immunoreactive bands. Actin was determined for each blot to verify equal protein loading.

\section{Statistical analysis}

All data are expressed as mean values with their standard errors. Differences between the group means were analysed by one-way ANOVA using the SAS statistical analysis program (SAS Institute, Cary, NC, USA). Differences between means were considered statistically significant at $P<0.05$. Duncan's multiple-range tests were used to determine the significance of differences in group means.

\section{Results}

Dietary conjugated linoleic acid improved insulin resistance

Although serum glucose concentrations were not significantly affected by CLA supplementation (Fig. 1 (A)), serum insulin levels were significantly $(P<0.05)$ decreased by the $c$ 9,t11-CLA-mix (Fig. 1 (B)). Furthermore, the degree of whole-body insulin resistance, assessed by serum insulin concentration, HOMA and R-QUICKI, was decreased in general by all three CLA preparations $(P<0.05)$ (Fig. 1 (C) and Fig. 1 (D)). All three CLA preparations reduced the value of HOMA, the index of insulin resistance. We also calculated another index for insulin sensitivity, R-QUICKI, by adding another parameter, NEFA. We previously reported modest decreases in the levels of serum NEFA and TG (Choi et al. 2004). R-QUICKI values were significantly higher in all three CLA groups than the HF group (Fig. 1 (D)). CLA did not affect serum adiponectin levels significantly. The group mean of serum adiponectin for the HF, CLA-mix, $c 9, t 11$ CLA-mix and $t 10, c 12$-CLA-mix group rats was $7 \cdot 18$ (SE 0.49), 9.49 (SE 1.81), 8.06 (SE 1.08) and 7.93 (SE 0.83) ng/ $\mathrm{ml}$ respectively. We previously reported that consumption of CLA for 8 weeks did not affect concentrations of TG and cholesterol in liver or skeletal muscle (Choi et al. 2004).

Dietary conjugated linoleic acid activated insulin signalling pathways and inhibited gluconeogenesis and glycogenolysis

In response to insulin, IRS-1 becomes tyrosine phosphorylated and then generates the major docking sites for the PI3-kinase. If the phosphorylation of IRS-1 on $\mathrm{Ser}^{307}$ is increased, the interaction between IRS-1 and the insulin receptor is markedly reduced. And the activity of PI3-kinase and then Akt phosphorylation is reduced (Gual et al. 2005; Lowell \& Shulman, 2005; Taniguchi et al. 2005). In the liver, all three CLA mixtures decreased IRS-1 serine phosphorylation (Fig. 2 (A) and Fig. 2 (B)). The decreases in IRS-1 serine phosphorylation 
(A)

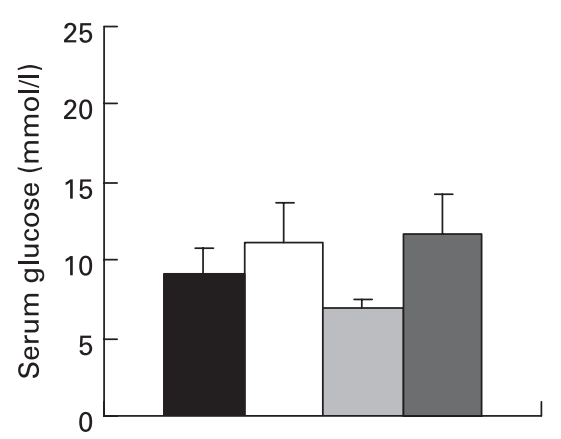

(C)

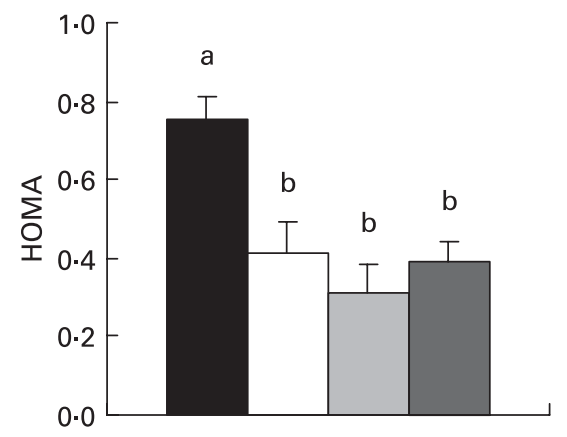

(B)

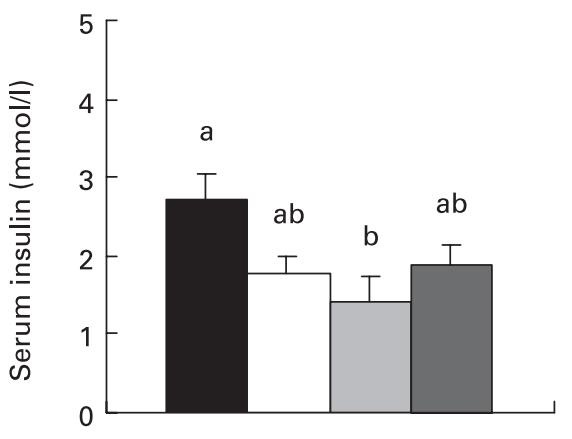

(D)

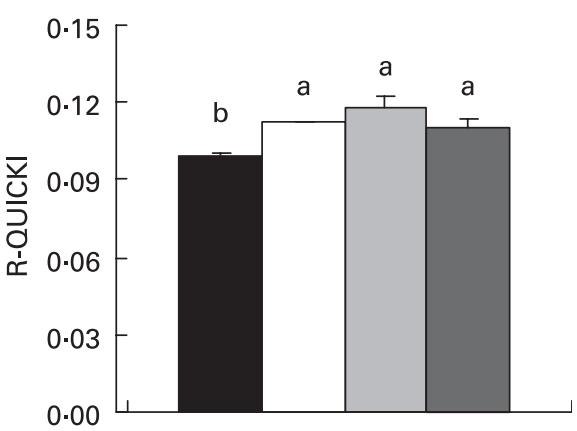

Fig. 1. Effect of three different conjugated linoleic acid (CLA) preparations on (A) serum glucose, (B) serum insulin, (C) homeostasis model assessment (HOMA) and (D) revised quantitative insulin-sensitivity check index (R-QUICKI) in rats fed a diet containing a high level of fat. ( $\square$ ), Unsupplemented high-fat diet; ( $\square$ ), CLAmix diet; $(\square)$, cis-9, trans-11-CLA-mix diet; $(\square)$, trans-10, cis-12-CLA-mix diet. Data are expressed as mean values with their standard errors represented by vertical bars $(n 4-5)$. Mean values with unlike letters are significantly different $(P<0.05$; ANOVA). For details of diets, see Materials and methods.

led to the improvement of insulin signalling. The $t 10, c 12-$ CLA-mix increased pAkt activation in the liver. In the muscle, all three CLA mixtures tended to decrease IRS-1 serine phosphorylation. Only the $t 10, c 12-C L A-m i x$ significantly decreased serine phosphorylation of IRS-1. It could be that liver is a more sensitive tissue than skeletal muscle in respect to the effect of CLA on insulin signalling.

Although the activities of glucose-6-phosphatase and phosphoenolpyruvate carboxykinase did not differ between groups (Fig. 2 (C)), the content of glycogen in the liver was greater in all CLA-treated groups than in the HF group, and significantly $(P<0 \cdot 05)$ greater in the CLA-mix and $c 9, t 11$-CLA-mix groups than in the HF group (Fig. 2 (D)). In muscle, serine phosphorylation of IRS-1 was significantly $(P<0.05)$ decreased in all CLA-supplemented groups but the phosphorylation of Akt was significantly activated by only the $t 10, c 12-C L A-$ mix (Fig. 3).

\section{Dietary conjugated linoleic acid increased expression of adiponectin receptors}

CLA supplementations did not change serum adiponectin concentrations, but we observed increases in AdipoR1 mRNA level by the $c 9, t 11$-CLA-mix and the $t 10, c 12$-CLA-mix and increases in AdipoR2 mRNA level by all three CLA mixtures $(P<0.05)$ (Fig. 4). The $c 9, t 11-C L A-m i x$ was the more potent of the two isomers for activation of AdipoR expression. We could not observe any modification of mRNA concentrations of AdipoR in muscle (Fig. 4).
Dietary conjugated linoleic acid influenced the activity of peroxisome proliferator-activated receptor- $\alpha$

The effect of adiponectin on insulin sensitivity is mainly mediated by AdipoR and may result in increased activation of PPAR $\alpha$ pathways and fatty acid oxidation (Kadowaki \& Yamaguchi, 2005). Although expressions of PPAR $\gamma$ and PPAR $\gamma$ coactivator $1 \alpha$ in the liver and muscle were not changed by CLA treatments, $\operatorname{PPAR} \alpha$ expression in liver and muscle was significantly $(P<0.05)$ increased by the $c 9, t 11$ CLA-mix (Fig. 5 (A) and Fig. 5 (B)).

Dietary conjugated linoleic acid increased messenger ribonucleic acid of genes associated with fatty acid oxidation and energy dissipation

Expression of peroxisomal acyl-CoA oxidase and UCP2 and UCP3 are regulated by PPAR $\alpha$ (Argyropoulos \& Harper, 2002). Among the three CLA mixtures, the $c 9, t 11$-CLA-mix was the most effective one to increase acyl-CoA oxidase mRNA level in the liver (Fig. $5(\mathrm{C})$ ).

Hepatic UCP2 mRNA level was increased by the CLA supplementations, but did not differ significantly between groups (Fig. 5 (C)). The muscle UCP2 mRNA level of the $c 9, t 11$ CLA-mix group (Fig. $5(\mathrm{C}))$ was significantly $(P<0.05)$ greater than that of the $\mathrm{HF}$ group, and was greater than those of the $t 10, c 12-C L A-m i x$ and CLA-mix groups. The CLA-mix group and the $c 9, t 11-C L A$ group had increased $(P<0.05)$ levels of UCP3 mRNA in the liver (Fig. $5(\mathrm{C})$ ). 
(A)

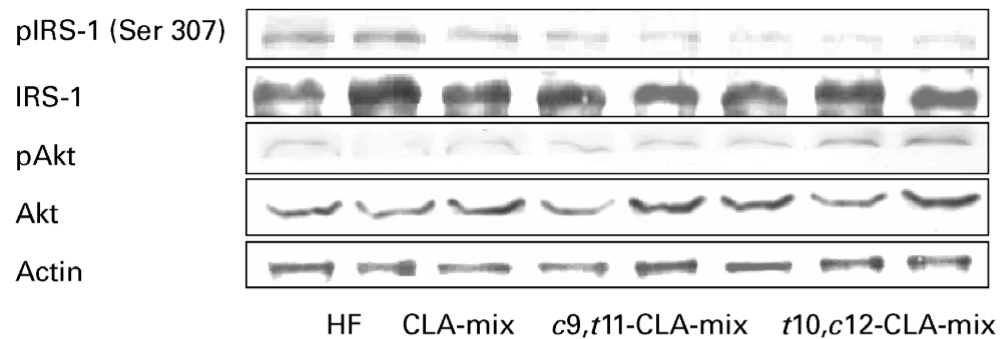

(B)

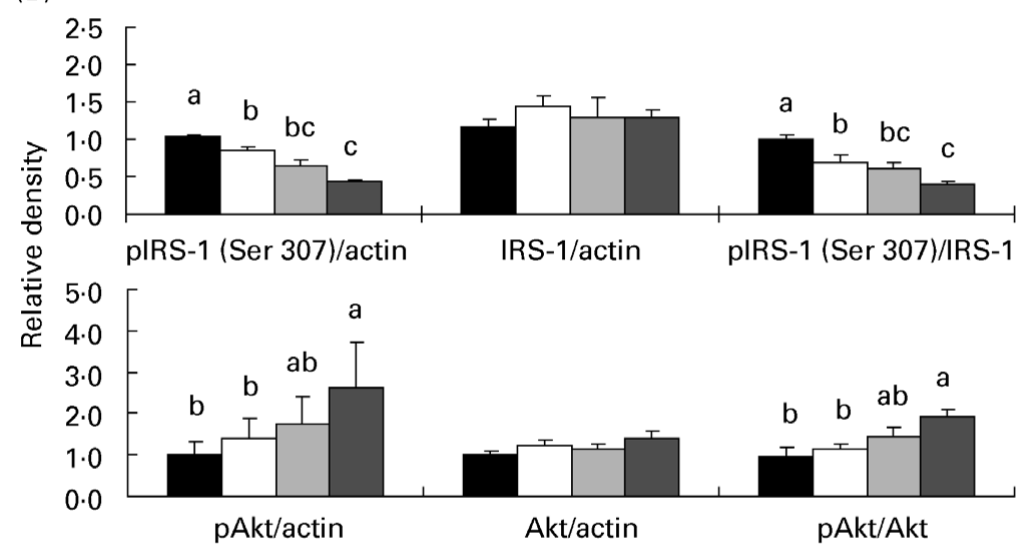

(C)

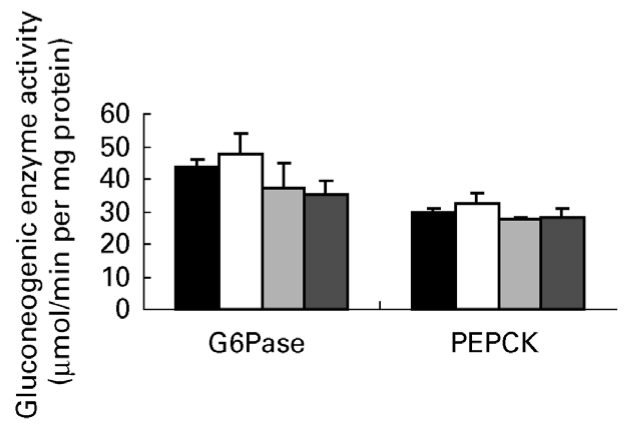

(D)

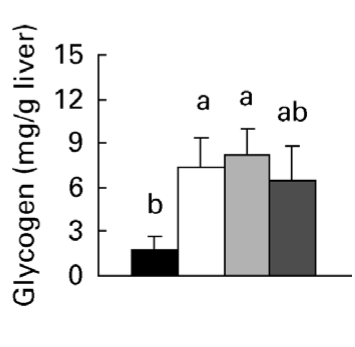

Fig. 2. Effect of three different conjugated linoleic acid (CLA) preparations (CLA-mix; cis-9, trans-11 (c9,t11)-CLA-mix; trans-10, cis-12 (t10,c12)-CLA-mix; for details of diets, see Materials and Methods) on insulin signalling proteins and glycogen content in livers of rats fed a diet containing a high level of fat. (A) Western analysis of liver. Representative immunoblots of p-insulin receptor substrate (IRS)-1 (Ser 307), total IRS-1, pAkt (Ser 473) and total Akt in liver. HF, unsupplemented high-fat diet. (B) Densitometry. Relative densities of pIRS-1 (Ser 307), total IRS-1, pAkt (Ser 473) and total Akt. ( $\square$ ), Unsupplemented high-fat diet; ( $\square$ ), CLAmix diet; ( $\square$ ), $c 9, t 11$-CLA-mix diet; $(\square), t 10, c 12-C L A-m i x$ diet. Data are expressed as mean values with their standard errors indicated by vertical bars ( $n$ 4-5). Mean values with unlike letters are significantly different $(P<0.05$; ANOVA). (C) Activities of glucose-6-phosphatase (G6Pase) and phosphoenolpyruvate carboxykinase (PEPCK). (D) Glycogen content. Mean values with unlike letters are significantly different $(P<0.05 ;$ ANOVA).

UCP3 mRNA levels in muscle tissue were not significantly different between groups (Fig. 5 (C)).

\section{Dietary conjugated linoleic acid enhanced activities of mitochondrial respiratory chain enzymes}

The $c 9, t 11$-CLA-mix and $t 10, c 12-C L A-m i x$ significantly $(P<0 \cdot 05)$ increased hepatic expression of SDH mRNA relative to that of the HF diet. The $c 9, t 11-C L A-m i x$ also significantly $(P<0.05)$ increased SDH mRNA expression in muscle (Fig. 6 (A)). However, the enzymic activity of SDH in liver and muscle was not greatly increased by CLA isomers. All CLA mixtures tended to increase mRNA levels of COX III
$(P<0.05)$ in the liver, but not in muscle (Fig. 6 (A)). COX activity in the liver was significantly $(P<0.05)$ greater in the $c 9, t 11-C L A-m i x$ group than in the HF group. All CLA preparations significantly $(P<0.05)$ increased COX activity in the muscle (Fig. 6 (B)).

\section{Dietary conjugated linoleic acid enhanced mitochondrial antioxidant capacities}

Although all three CLA mixtures did not decrease the level of mitochondrial malondialdehyde, the $c 9, t 11-C L A-m i x$ significantly $(P<0.05)$ increased the level of GSH in the liver (Fig. 7 (A) and Fig. 7 (B)). The hepatic activities of 
(A)

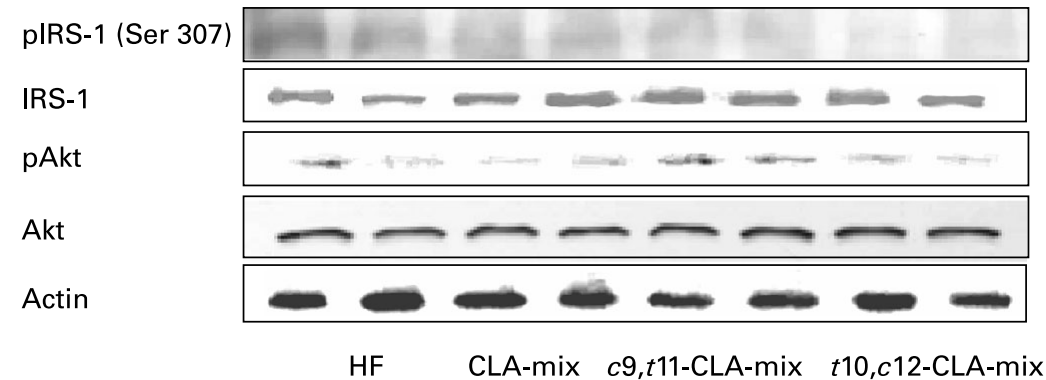

(B)

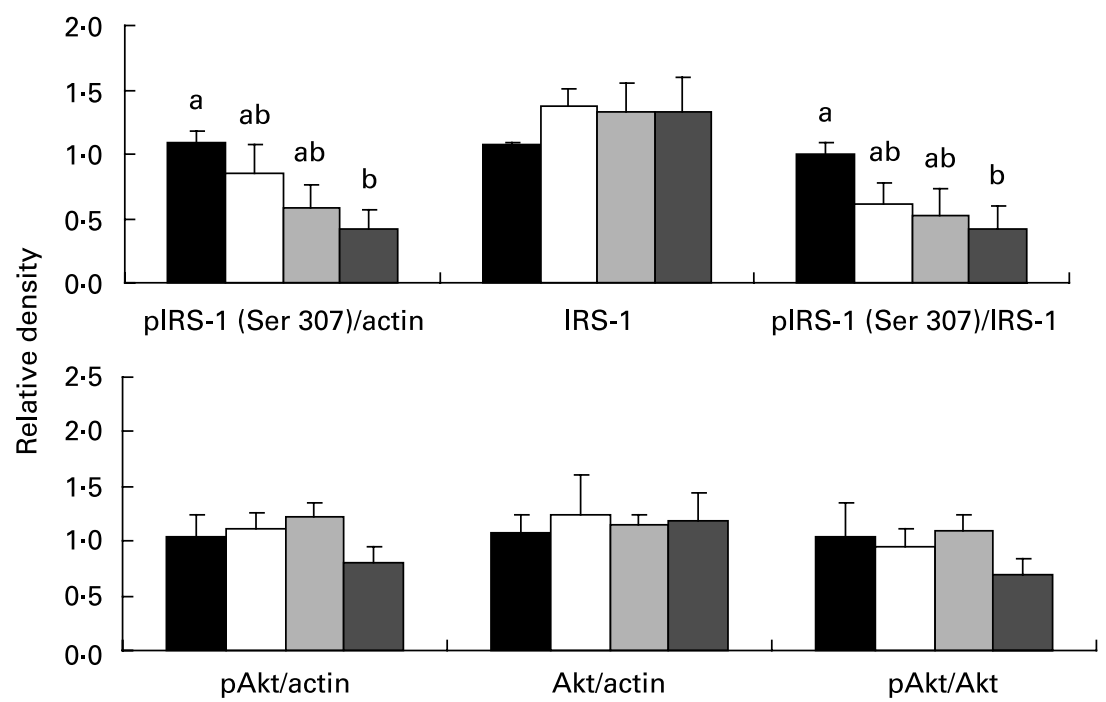

Fig. 3. Effect of three different conjugated linoleic acid (CLA) preparations (CLA-mix; cis-9, trans-11 (c9,t11)-CLA-mix; trans-10, cis-12 (t10,c12)-CLA-mix; for details of diets, see Materials and Methods) on insulin signalling proteins in muscle of rats fed a diet containing a high level of fat. (A) Western analysis of muscle. Representative immunoblots of p-insulin receptor substrate (IRS)-1 (Ser 307), total IRS-1, pAkt (Ser 473) and total Akt in muscle. HF, unsupplemented high-fat

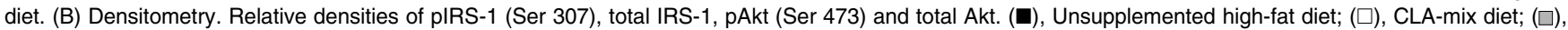
$c 9, t 11-C L A-m i x ~ d i e t ; ~(\square), t 10, c 12-C L A-m i x ~ d i e t$. Data are expressed as mean values with their standard errors indicated by vertical bars $(n 4-5)$. Mean values with unlike letters are significantly different $(P<0.05$; ANOVA).

manganese-superoxide dismutase, GPx, and GR were significantly greater in the $c 9, t 11$-CLA group than in the HF group (Fig. 7 (A)) $(P<0 \cdot 05)$. The activity of manganese-superoxide dismutase in muscle mitochondria was also significantly $(P<0.05)$ greater in the $c 9, t 11-C L A-m i x$ group than in the HF group (Fig. 7 (B)). These data suggest that the $c 9, t 11$ CLA-mix improved mitochondrial function by increasing levels of GSH and activities of antioxidative enzymes.

\section{Discussion}

Dietary CLA has positive effects on body weight and fat deposition (Sisk et al. 2001). There is much interest in the potential use of CLA to alleviate insulin resistance. We observed that inclusion of CLA in the HF diet reduced insulin resistance by improving one or several aspects of insulin signalling, fatty acid oxidation and mitochondrial antioxidant capacity. Because the effects of CLA on insulin resistance may differ between isomers, we investigated the role of three different CLA preparations on insulin resistance in rats fed a diet with an HF content. Three commercially available CLA supplements contained different ratios of the $c 9, t 11-\mathrm{CLA}$ isomer and $t 10, c 12-C L A$ isomer. CLA-mix, $c 9, t 11$-CLA-mix and $t 10, c 12-C L A-m i x$ contained the $c 9, t 11-C L A$ and $t 10, c 12$-CLA isomers at the ratios of 30:40, 80:20 and 10:90 respectively. All our three CLA mixtures significantly improved insulin resistance based on the values of HOMA and R-QUICKI. There are several contradictory results of studies on the effects of CLA on insulin resistance. While many studies have shown harmful effects of CLA on insulin sensitivity in mice models, some beneficial effects can be observed in rat models (Houseknecht et al. 1998; Ryder et al. 2001; Nagao et al. 2003a; Wargent et al. 2005; Poirier et al. 2006). Since mice rapidly lost fat mass together with hepatomegaly, differential effects of CLA on insulin sensitivity could be explained partly by animal differences (Tsuboyama-Kasaoka et al. 2000). Based on the size of organisms, the effect of CLA on insulin resistance in the rat model might reflect the changes in man better than in the mouse model. The rat model has shown beneficial effects of CLA on insulin resistance. For example, in a Zucker diabetic fatty (ZDF) rat model for obesity and diabetes, providing a 
(A)

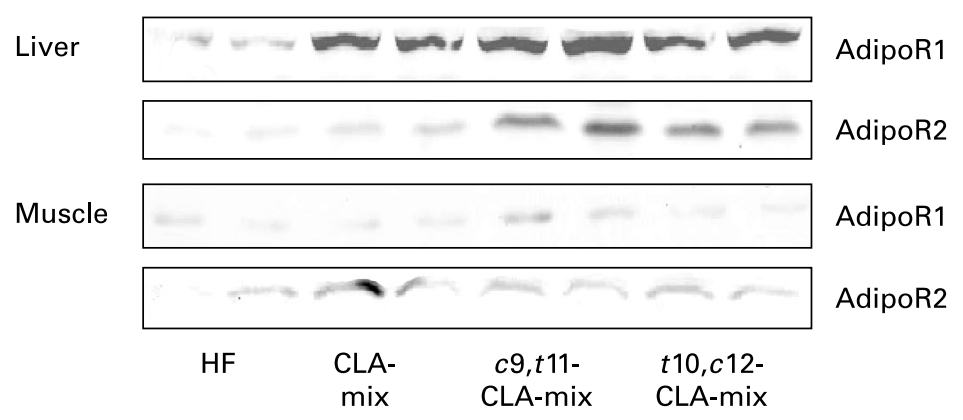

(B)

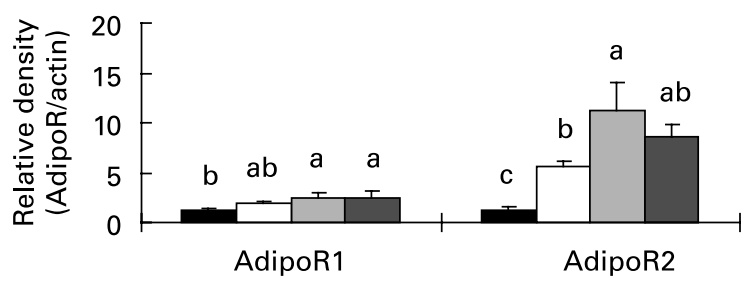

(C)

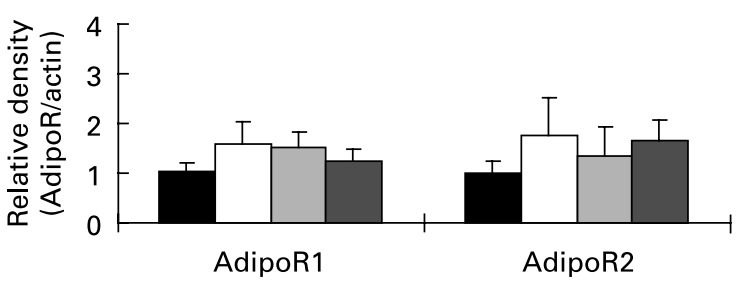

Fig. 4. Effect of three different conjugated linoleic acid (CLA) preparations (CLA-mix; cis-9, trans-11 (c9,t11)-CLA-mix; trans-10, cis-12 (t10,c12)-CLA-mix; for details of diets, see Materials and Methods) on adiponectin receptor (AdipoR) 1 and AdipoR2 levels in liver and muscle of rats fed a diet containing a high level of fat. (A) Western analysis. Representative immunoblots of AdipoR1 and AdipoR2. HF, unsupplemented high-fat diet. (B) Densitometry. Relative densities of Adi-

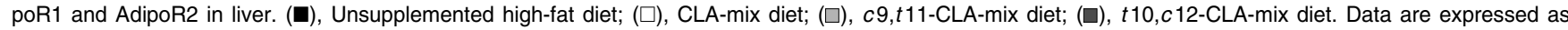
mean values with their standard errors indicated by vertical bars $(n 5)$. Mean values with unlike letters are significantly different $(P<0.05$; ANOVA). (C) Densitometry. Relative densities of AdipoR1 and AdipoR2 in muscle.

50:50 CLA mix at $1.5 \%$ diet improved glucose tolerance and insulin sensitivity, and decreased fasting glucose and insulin levels (Houseknecht et al. 1998, Ryder et al. 2001). Nagao et al. (2003a) showed that CLA attenuated plasma glucose and insulin and prevented hyperinsulinaemia by enhancing plasma adiponectin levels and mRNA expression in white adipose tissue from Zucker diabetic fatty rats. However, in mouse models, the intake of $t 10, c 12-C L A$ in ob/ob mice elevated serum glucose and insulin levels and induced insulin resistance (Roche et al. 2002; Poirier et al. 2006). In a recent study (Wargent et al. 2005), supplementation of $1.5 \%$ CLA mix or $t 10, c 12-C L A-e n r i c h e d$ CLA for 2 weeks elevated fasting glucose and insulin levels of genetically obese C57BL/6 lepob/lepob mice. However, when supplementation was continued for 10 weeks, CLA had beneficial effects on both glucose and insulin levels. The study suggests that although initially CLA may have negative effects on insulin resistance, long-term treatment with CLA could improve insulin sensitivity and glucose tolerance. Furthermore, the effects of CLA may be dependent on the fat content of the diet. In human studies, CLA may decrease insulin sensitivity in obese men (Riserus et al. 2002), but CLA improves insulin sensitivity in sedentary human subjects (Eyjolfson et al.
2004). Therefore, experimental conditions such as the proportion of CLA in the diets, strain of animal, metabolic state of the subjects (normal $v$. obese and diabetic) and duration of CLA feeding could contribute to the different results between studies. More studies are required to fully understand the mechanisms involved in the beneficial or deleterious effects of CLA and the purified isomers on insulin resistance.

The effect of CLA on insulin signalling events has not been subject to extensive study. In a cancer cell, CLA inhibits the activation of PI3-kinase, Akt, cell growth and tumour growth (Cho et al. 2003). Chung et al. (2005) reported that $t 10, c 12-C L A$ decreased the IRS- 1 and Glut- 4 content of adipose cells but had no effect on the phosphorylation of IRS-1 (Ser 307 or Tyr 891) or Akt (Ser 473), suggesting that CLA does not affect insulin signal transduction per se. However, Chung's results were derived from cell cultures under in vitro conditions. In the present in vivo experiment, all three CLA mixtures decreased serine phosphorylation of IRS-1 and tended to increase the phosphorylation of Akt in the liver. The $t 10, c 12-C L A-m i x$ was more effective than the $c 9, t 11$-CLA-mix in activating the insulin signalling pathway. An activation of Akt by phosphorylation led to the inactivation of glycogen synthase kinase-3. Inactivated glycogen synthase 
(A)

Liver

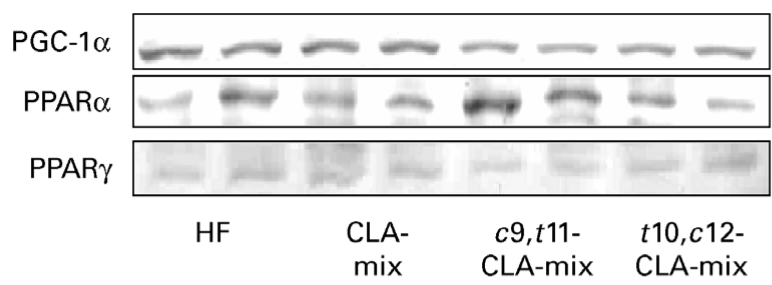

Muscle
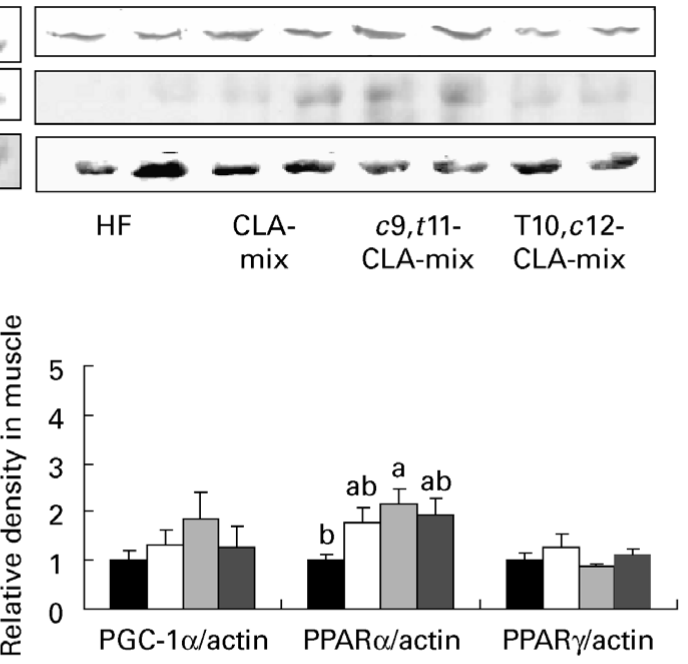

(C)
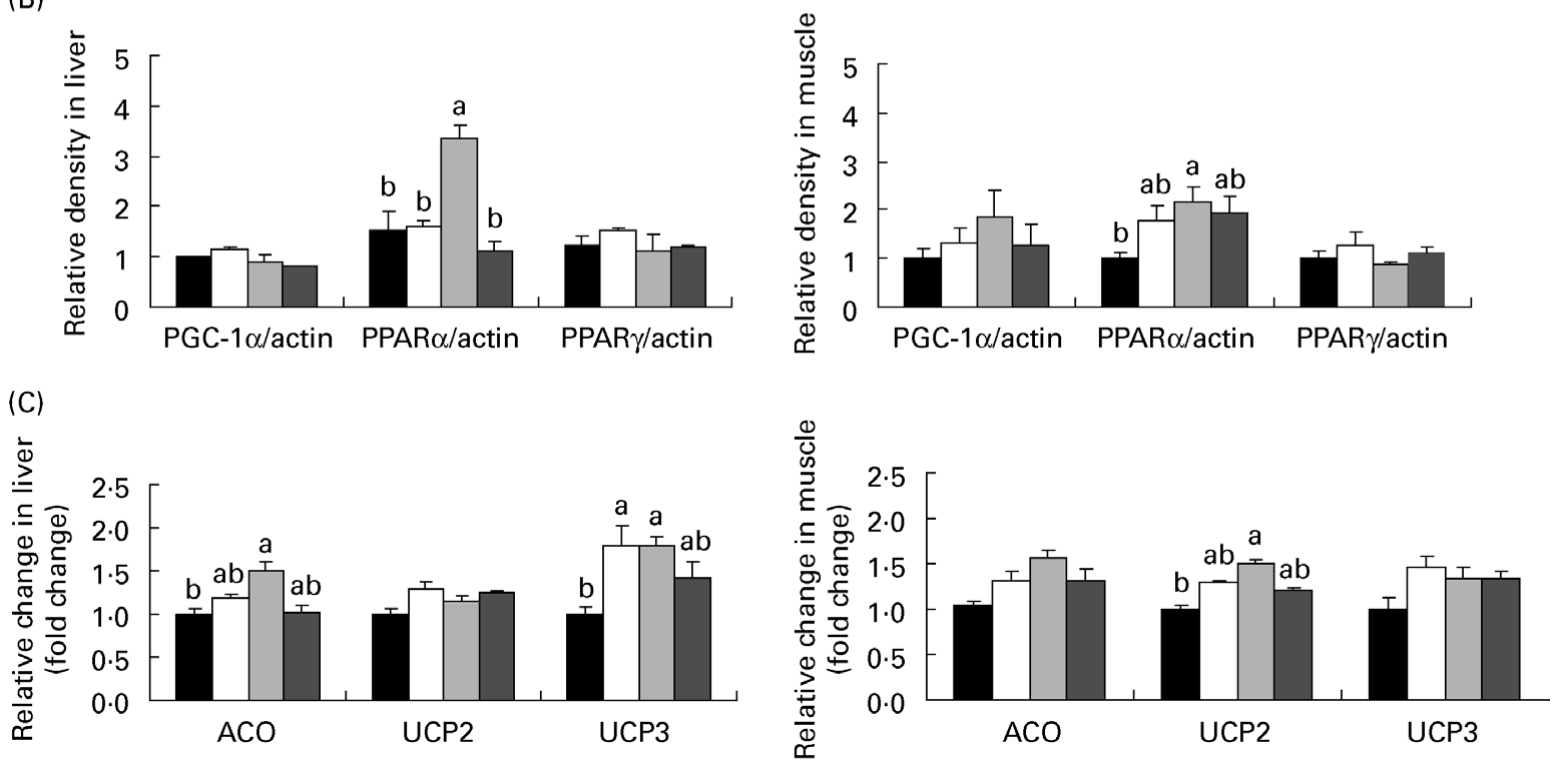

Fig. 5. Effect of three different conjugated linoleic acid (CLA) preparations (CLA-mix; cis-9, trans-11 (c9,t11)-CLA-mix; trans-10, cis-12 (t10,c12)-CLA-mix; for details of diets, see Materials and Methods) on PPAR $\gamma$ coactivator $1 \alpha$ (PGC-1 $\alpha)$, PPAR $\alpha$ and PPAR $\gamma$ protein levels and expression of downstream target genes in liver and muscle of rats fed a diet containing a high level of fat. (A) Western analysis. Representative immunoblots of PGC-1 $\alpha$, PPAR $\alpha$ and PPAR $\gamma$. HF, unsupplemented high-fat diet. (B) Densitometry. Relative densities of PGC-1 $\alpha$, PPAR $\alpha$ and PPAR $\gamma$. (ロ), Unsupplemented high-fat diet; ( $\square$ ), CLA-mix diet; ( $\square$ ), $c 9, t 11-$

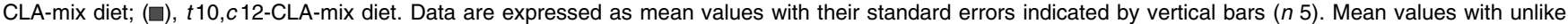
letters are significantly different ( $P<0.05$; ANOVA). (C) RT-PCR. Relative changes in mRNA expression of acyl-CoA oxidase (ACO) and uncoupling protein (UCP) in liver and muscle. Mean values with unlike letters are significantly different $(P<0.05$; ANOVA).

kinase-3 led to less phosphorylated glycogen synthase. Inhibiting the phosphorylation of glycogen synthase increases the synthesis of glycogen and decreases in hepatic glycogenolysis (Henriksen \& Dokken, 2006).

Impaired hepatic glycogen storage and dysregulated glycogen synthesis is a critical feature of diabetes mellitus, as glycogen synthesis rates of diabetic patients are about $50 \%$ of the values in healthy subjects (Bogardus et al. 1984; Damsbo et al. 1991). In the present study, diets supplemented with the CLAmix and the $c 9, t 11$-CLA-mix resulted in greater hepatic glycogen accumulation than the unsupplemented diet. This pattern, which mirrors that of Akt activation, suggests that CLA improves the insulin resistance induced by the HF diet. However, Akt in skeletal muscle was not activated by all three CLA mixtures. Consequently, we presume that CLA mixtures, especially the $t 10, c 12$-CLA-mix, activate IRS- 1 in both liver and muscle. The downstream Akt activation was affected by the $t 10, c 12$-CLA-mix only in the liver.

Adiponectin promotes fatty acid oxidation in liver and muscle and inhibits hepatic glucose production (Yamauchi et al. 2003; Kadowaki \& Yamaguchi, 2005). Adiponectin may act through binding to its receptors in tissues, which may regulate insulin sensitivity. Two AdipoR, AdipoR1 and AdipoR2, were recently identified in many tissues, including liver and muscle
(Kadowaki \& Yamaguchi, 2005). In mice, AdipoR1 is ubiquitously expressed but is most abundant in skeletal muscle, while AdipoR2 is primarily expressed in the liver. In contrast, in rats and man, both receptors are highly expressed in muscle and liver. Expressions of AdipoR is decreased in insulin-resistant animals and is correlated with decreased adiponectin binding to membrane fractions, AMP kinase activation and acetyl CoA carboxylase phosphorylation in skeletal muscle and liver, activating fatty acid oxidation and glucose uptake in muscle and liver and inhibiting gluconeogenesis in liver. In addition, adiponectin increases the expression of PPAR $\alpha$ and its target genes, resulting in reduced liver and muscle TG content (Yamauchi et al. 2003; You \& Crabb, 2004; Kadowaki \& Yamaguchi, 2005). There are few studies of the effects of CLA on the expression and serum concentrations of adiponectin. Decreases in AdipoR expression impair the metabolic effects of adiponectin (Yamauchi et al. 2003; Inukai et al. 2005). Beylot et al. (2006) also stated that along with the levels of adiponectin expression and plasma adiponectin, the levels of AdipoR expression could control insulin sensitivity. The expressions of AdipoR1 and R2 in ob/ob mice were significantly decreased in skeletal muscle and adipose tissue, which was correlated with decreased adiponectin binding to membrane fractions of skeletal muscle and decreased AMP kinase activation by adiponectin. 
(A)

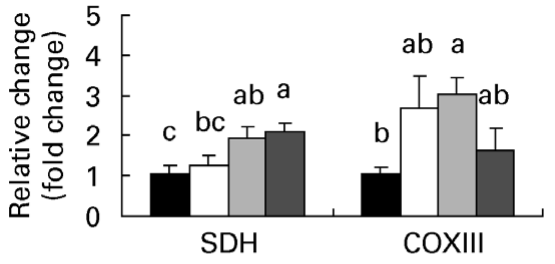

Liver

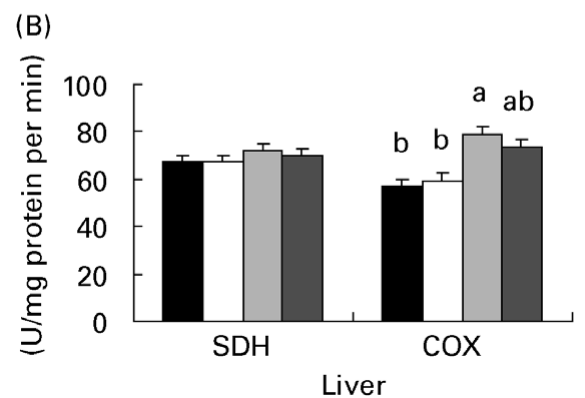

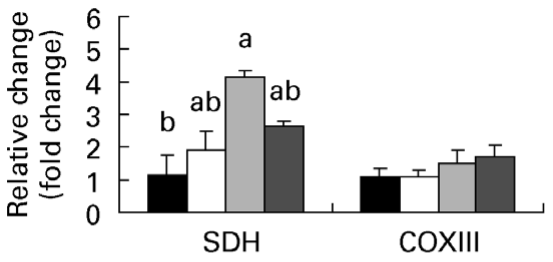

Muscle

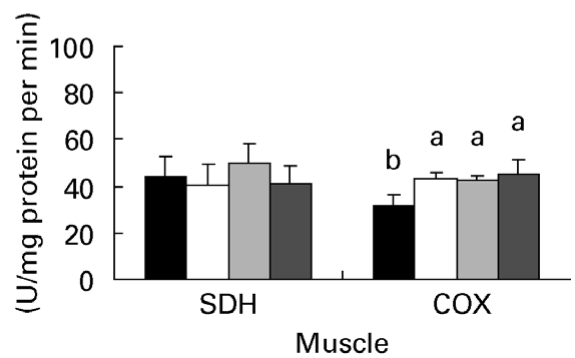

Fig. 6. Effect of three different conjugated linoleic acid (CLA) preparations on enzymic activities of succinate dehydrogenase (SDH) and cytochrome $c$ oxidase (COX) in liver and muscle of rats fed a diet containing a high level of fat. (A) Real-time RT-PCR. Relative changes in mRNA expression of SDH and COXIII. ( $\square$ ), Unsupplemented high-fat diet; $(\square)$, CLA-mix diet; ( $\square$ ), cis-9, trans-11-CLA-mix diet; $(\square)$, trans-10, cis-12-CLA-mix diet. Data are expressed as mean values with their standard errors indicated by vertical bars $(n 5)$. Mean values with unlike letters are significantly different $(P<0 \cdot 05 ;$ ANOVA). (B) Kinetic analysis. Enzyme activities of $\mathrm{SDH}$ and $\mathrm{COX}$. Mean values with unlike letters are significantly different $(P<0.05$; ANOVA). For details of diets, see Materials and Methods.

This adiponectin resistance in turn may play a role in worsening insulin resistance in ob/ob mice (Tsuchida et al. 2004).

In the present study, serum adiponectin concentrations were not affected by any CLA mixture, neither could we observe any modification of mRNA levels of AdipoR in muscle. Although the expression of AdipoR in rats is poorly responsive to changes in nutritional conditions contrary to what was reported in mice, HF diet feeding decreased AdipoR2 mRNA level in the liver of Wistar rats (Beylot et al. 2006). We could also observe effects of CLA treatments on AdipoR mRNA levels in the liver. We observed the increases in AdipoR 1 mRNA level by the $c 9, t 11$-CLA-mix and $t 10, c 12$ CLA-mix and the increases in AdipoR2 mRNA level by all three CLA mixtures. These changes suggest that the improved insulin sensitivity observed in the CLA groups may be related to the levels of hepatic AdipoR. Increased binding of AdipoR by CLA might affect the action of PPAR $\alpha$. CLA may increase fatty acid oxidation through increased hepatic AdipoR1 and AdipoR2 protein expression. Dietary $c 9, t 11$-CLA-mix increased protein and mRNA expression of PPAR $\alpha$ in the liver and the expression of mRNA of acyl-CoA oxidase, and UCP-2 and UCP-3, enzymes that are involved in fat oxidation. It is probable that the divergent effects of CLA isomers on insulin and glucose metabolism reflect differences between the metabolic effects of $c 9, t 11-C L A$ and $t 10, c 12-C L A$. We observed that the $t 10, c 12-C L A-m i x$ improved insulin signalling. $c 9, t 11-$ CLA, in addition to improving glucose metabolism, improved lipid metabolism and resulted in less fat deposition through up regulation of hepatic PPAR $\alpha$, acylCoA oxidase and UCP. Up regulation of UCP is thought to prevent fat deposition by dissipating energy as heat (Argyropoulos \& Harper, 2002).

Dysfunctional mitochondria decrease energy production and contribute to insulin resistance (Wallace, 2001; Lossa et al.
2003; Petersen et al. 2004; Lowell \& Shulman, 2005; Wisloff et al. 2005). We studied the effects of the HF diet and CLA supplementation on mitochondrial gene expression, respiratory chain complex activity and antioxidative status. Impairment of electron transport by the HF diet might have increased formation of reactive oxygen species (ROS) in mitochondria, depleted antioxidants, and impaired the flow of electrons, propagating an increasing rate of mitochondrial ROS formation (Lossa et al. 2003). CLA modulated HF-induced mitochondrial dysfunction in liver and muscle, resulting in greater energy production capacity with less production of ROS. The $c 9, t 11-$ CLA-mix significantly increased both SDH and COXIII mRNA levels and increased the COX activity of liver and muscle compared with the CLA mix and $t 10, c 12-C L A-m i x$. Among the three CLA mixtures, the $c 9, t 11$-CLA-mix resulted in the greatest improvement of COX activity in the liver. Mitochondria produce ROS during energy production, which makes them susceptible to oxidative damage. Because the $c 9, t 11-\mathrm{CLA}-$ mix increased mitochondrial activity, we examined how the three different CLA preparations affect overall antioxidant capacity. Results of studies on the effects of CLA on antioxidant status are contradictory (Palacios et al. 2003; Bergamo et al. 2004; Yamasaki et al. 2005). However, CLA protected mitochondria isolated from rat liver from peroxidative damage and dietary CLA improved the antioxidant status of rats deficient in vitamin E (Palacios et al. 2004; Kim et al. 2005). We found that the $c 9, t 11$-CLA-mix increased the activities of the mitochondrial antioxidant enzymes, manganese-superoxide dismutase, GPx, and GR, the level of GSH, and decreased malondialdehyde production in the mitochondria of liver and muscle. The increased expression of UCP induced by the $c 9, t 11$-CLA-mix in the present study may also promote the removal of ROS, because UCP are thought to reduce ROS accumulation (MacLellan et al. 2005). 
(A)
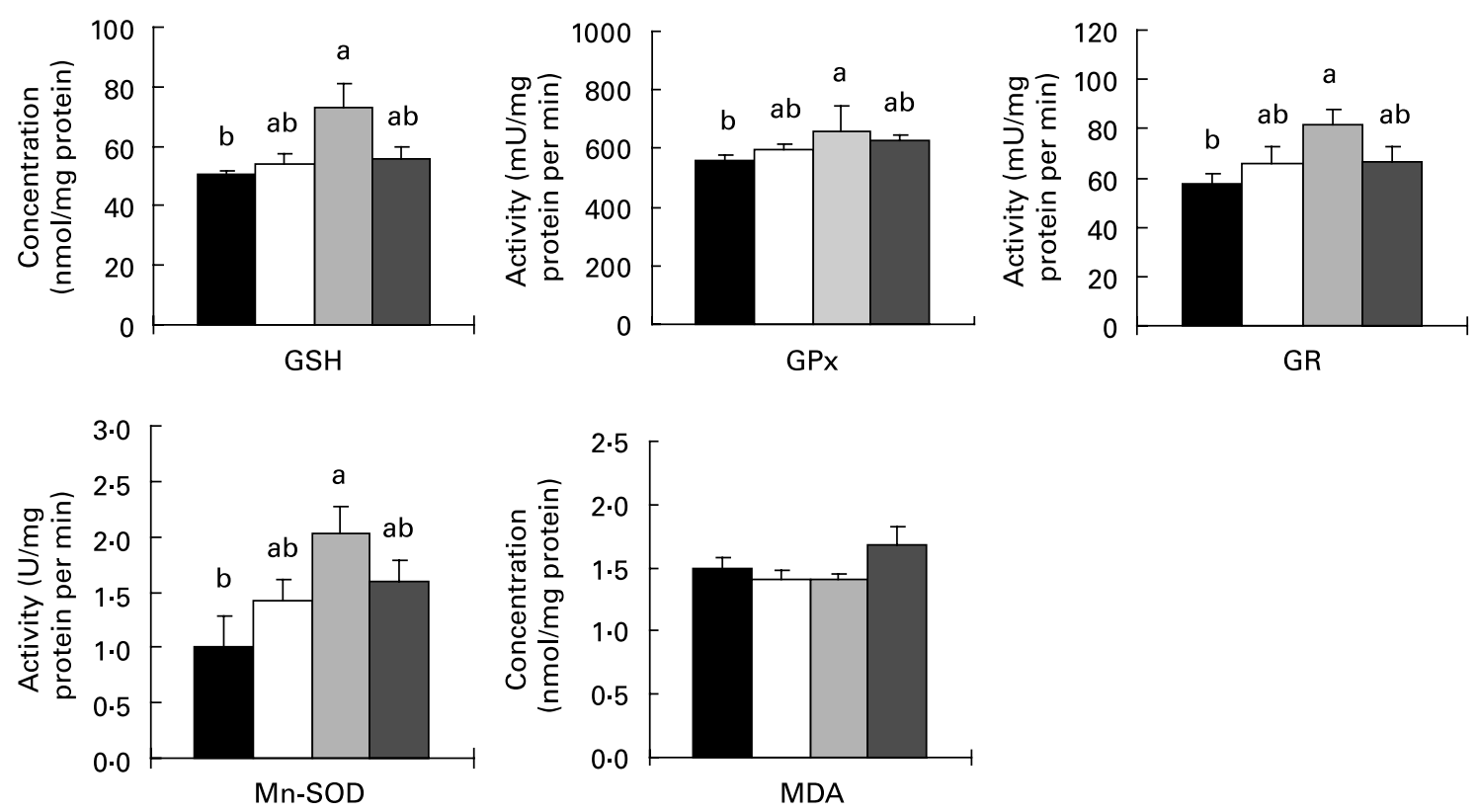

(B)
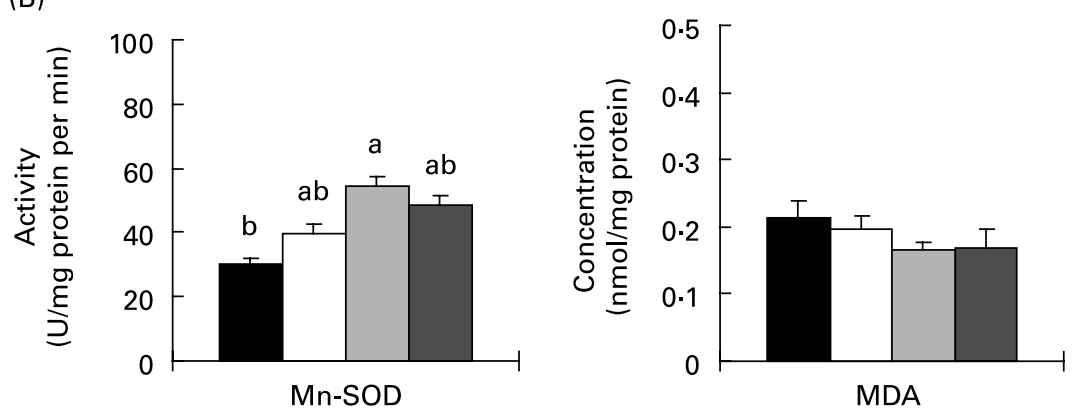

Fig. 7. Effect of three different conjugated linoleic acid (CLA) preparations on mitochondrial antioxidant capacities in liver and muscle of rats fed a diet containing a high level of fat. Mitochondrial enzymic activities of manganese-superoxide dismutase (Mn-SOD), glutathione peroxidase (GPx) and glutathione reductase (GR) and levels of GSH and malondialdehyde (MDA) in liver (A) and muscle (B). ( $\square$ ), Unsupplemented high-fat diet; ( $\square$ ), CLA-mix diet; ( $\square$ ), cis-9, trans-11-CLA-mix diet; ( $\square)$, trans-10, cis-12-CLA-mix diet. Data are expressed as mean values with their standard errors indicated by vertical bars $(n 5)$. Mean values with unlike letters are significantly different $(P<0.05$; ANOVA). For details of diets, see Materials and Methods.

In conclusion, the present findings suggest that the $c 9, t 11$ CLA-mix and $t 10, c 12-C L A-m i x$ activated the insulin signalling pathway in the liver by decreasing serine phosphorylation of IRS- 1 . The $t 10, c 12-C L A-m i x$ especially activated Akt. The $c 9, t 11-C L A-m i x$ also increased the sensitivity of AdipoR1 and AdipoR2 for adiponectin, resulting in an increase in PPAR $\alpha$ ligand activity and fatty acid oxidation. The $c 9, t 11$-CLA-mix was the most effective in promoting energy production and thermogenesis because it activated the mitochondrial respiratory chain and fat oxidation, which resulted in less fat accumulation and improved whole-body insulin resistance. The $c 9, t 11-C L A-m i x$ also reduced the production of ROS by increasing antioxidant capacity.

\section{Acknowledgements}

The present study was supported in part by a Korea National Institute of Health intramural research grant
(347-6111-211-207) and a grant from the Korea Health 21 R\&D Project, Ministry of Health \& Welfare, Republic of Korea (03-PJ1-PG3-22 000-0014).

\section{References}

Argyropoulos G \& Harper ME (2002) Uncoupling proteins and thermoregulation. J Appl Physiol 92, 2187-2198.

Baginski ES, Foa PP \& Zak B (1974) Glucose-6-phosphatase. In Methods of Enzymatic Analysis, vol. 2, pp. 876-881 [HU Bergmeyer, editor]. New York: Academic Press.

Bergamo P, Luongo D \& Rossi M (2004) Conjugated linoleic acidmediated apoptosis in Jurkat $\mathrm{T}$ cells involves the production of reactive oxygen species. Cell Physiol Biochem 14, 57-64.

Beylot M, Pinteur C \& Peroni O (2006) Expression of the adiponectin receptors AdipoR1 and AdipoR2 in lean rats and in obese Zucker rats. Metabolism 55, 396-401.

Bogardus C, Lillioja S, Stone K \& Mott D (1984) Correlation between muscle glycogen synthase activity and in vivo insulin action in man. J Clin Invest 73, 1185-1190. 
Chang HC \& Lane MD (1966) The enzymatic carboxylation of phosphoenolpyruvate. II. Purification and properties of liver mitochondrial phosphoenolpyruvate carboxykinase. J Biol Chem 241, 2413-2420.

Cho HJ, Kim WK, Kim EJ, Jung KC, Park S, Lee HS, Tyner AL \& Park JH (2003) Conjugated linoleic acid inhibits cell proliferation and ErbB3 signaling in HT-29 human colon cell line. Am J Physiol 284, G996-G1005.

Choi JS, Jung MH, Park HS \& Song J (2004) Effect of conjugated linoleic acid isomers on insulin resistance and mRNA levels of genes regulating energy metabolism in high-fat-fed rats. Nutrition 20, 1008-1017.

Chung S, Brown JM, Provo JN, Hopkins R \& McIntosh MK (2005) Conjugated linoleic acid promotes human adipocyte insulin resistance through $\mathrm{NF \kappa B}$-dependent cytokine production. $\mathrm{J}$ Biol Chem 280, 38445-38456.

Damsbo P, Vaag A, Hother-Nielsen O \& Beck-Nielsen H (1991) Reduced glycogen synthase activity in skeletal muscle from obese patients with and without type 2 (non-insulin-dependent) diabetes mellitus. Diabetologia 34, 239-245.

de Roos B, Rucklidge G, Reid M, et al. (2005) Divergent mechanisms of cis 9 , trans 11 - and trans 10, cis12-conjugated linoleic acid affecting insulin resistance and inflammation in apolipoprotein $\mathrm{E}$ knockout mice: a proteomics approach. FASEB J 19, 1746-1748.

Ealey KN, El-Sohemy A \& Archer MC (2002) Effects of dietary conjugated linoleic acid on the expression of uncoupling proteins in mice and rats. Lipids 37, 853-861.

Eyjolfson V, Spriet LL \& Dyck DJ (2004) Conjugated linoleic acid improves insulin sensitivity in young, sedentary humans. Med Sci Sports Exerc 36, 814-820.

Ford ES (2004) The metabolic syndrome and mortality from cardiovascular disease and all-causes: findings from the National Health and Nutrition Examination Survey II Mortality Study. Atherosclerosis 173, 309-314.

Grundy SM (2004) Obesity, metabolic syndrome, and cardiovascular disease. J Clin Endocrinol Metab 89, 2595-2600.

Gual P, Le Marchand-Brustel Y \& Tanti JF (2005) Positive and negative regulation of insulin signaling through IRS-1 phosphorylation. Biochimie 87, 99-109.

Heidelberger M, Msenberg AC \& Hassid WZ (1954) Glycogen, an immunologically specific polysaccharide. J Exp Med 99, 343-353.

Henriksen EJ \& Dokken BB (2006) Role of glycogen synthase kinase- 3 in insulin resistance and type 2 diabetes. Curr Drug Targets 7, 1435-1441.

Houseknecht KL, Vanden Heuvel JP, Moya-Camarena SY, Portocarrero CP, Peck LW, Nickel KP \& Belury MA (1998) Dietary conjugated linoleic acid normalizes impaired glucose tolerance in the Zucker diabetic fatty fa/fa rat. Biochem Biophys Res Commun 244, 678-682.

Inukai K, Nakashima Y, Watanabe M, Takata N, Sawa T, Kurihara S, Awata T \& Katayama S (2005) Regulation of adiponectin receptor gene expression in diabetic mice. Am J Physiol 288, E876-E882.

Kadowaki T \& Yamaguchi T (2005) Adiponectin and adiponectin receptors. Endocr Rev 26, 439-451.

Kim HK, Kim SR, Ahn JY, Cho IJ, Yoon CS \& Ha TY (2005) Dietary conjugated linoleic acid reduces lipid peroxidation by increasing oxidative stability in rats. $J$ Nutr Sci Vitaminol 51, 8-15.

Larsen TM, Toubro S \& Astrup A (2003) Efficacy and safety of dietary supplements containing CLA for the treatment of obesity: evidence from animal and human studies. J Lipid Res 44, 2234-2241.

Lossa S, Lionetti L, Mollica MP, Crescenzo R, Botta M, Barletta A \& Liverini G (2003) Effect of high-fat feeding on metabolic efficiency and mitochondrial oxidative capacity in adult rats. $\mathrm{Br} \mathrm{J}$ Nutr 90, 953-960.

Lowell BB \& Shulman GI (2005) Mitochondrial dysfunction and type 2 diabetes. Science 307, 384-387.

MacLellan JD, Gerrits MF, Gowing A, Smith PJ, Wheeler MB \& Harper ME (2005) Physiological increases in uncoupling protein
3 augment fatty acid oxidation and decrease reactive oxygen species production without uncoupling respiration in muscle cells. Diabetes 54, 2343-2350.

Matthews DR, Hosker JP \& Rudenski AS (1985) Homeostasis model assessment: insulin resistance and $\beta$-cell function from fasting plasma glucose and insulin concentrations in man. Diabetologia 28, 412-419.

Moloney F, Yeow TP, Mullen A, Nolan JJ \& Roche HM (2004) Conjugated linoleic acid supplementation, insulin sensitivity, and lipoprotein metabolism in patients with type 2 diabetes mellitus. Am J Clin Nutr 80, 887-895.

Nagao K, Inoue N, Wang YM \& Yanagita T (2003a) Conjugated linoleic acid enhances plasma adiponectin level and alleviates hyperinsulinemia and hypertension in Zucker diabetic fatty (fa/ fa) rats. Biochem Biophys Res Commun 310, 562-566.

Nagao K, Wang YM, Inoue N, Han SY, Buang Y, Noda T, Kouda N, Okamatsu H \& Yanagita T (2003b) The 10trans, 12cis isomer of conjugated linoleic acid promotes energy metabolism in OLETF rats. Nutrition 19, 652-656.

Owen P \& Freer JH (1970) Factors influencing the activity of succinate dehydrogenase in membrane preparations from Micrococcus lysodeikticus. Biochem J 120, 237-243.

Palacios A, Piergiacomi V \& Catala A (2003) Antioxidant effect of conjugated linoleic acid and vitamin A during non enzymatic lipid peroxidation of rat liver microsomes and mitochondria. Mol Cell Biochem 250, 107-113.

Perseghin G, Caumo A, Caloni M, Testolin G \& Luzi L (2001) Incorporation of the fasting plasma FFA concentration into QUICKI improves its association with insulin sensitivity in nonobese individuals. J Clin Endocrinol Metab 86, 4776-4781.

Petersen KF, Dufour S, Befroy D, Garcia R \& Shulman GI (2004) Impaired mitochondrial activity in the insulin-resistant offspring of patients with type 2 diabetes. $N$ Engl J Med 350, 664-671.

Plum L, Giesen K, Kluge R, Junger E, Linnartz K, Schurmann A, Becker W \& Joost HG (2002) Characterisation of the mouse diabetes susceptibility locus Nidd/SJL: islet cell destruction, interaction with the obesity QTL Nob1, and effect of dietary fat. Diabetologia 45, 823-830.

Poirier H, Shapiro JS, Kim RJ \& Lazar MA (2006) Nutritional supplementation with trans-10, cis-12-conjugated linoleic acid induces inflammation of white adipose tissue. Diabetes 55, 1634-1641.

Rainer L \& Heiss CJ (2004) Conjugated linoleic acid: health implications and effects on body composition. J Am Diet Assoc 104, 963-968.

Riserus U, Arner P, Brismar K \& Vessby B (2002) Treatment with dietary trans 10 cis 12 conjugated linoleic acid causes isomerspecific insulin resistance in obese men with the metabolic syndrome. Diabetes Care 25, 1516-1521.

Roche HM, Noone E, Sewter C, McBennett S, Savage D, Gibney MJ, O'Rahilly S \& Vidal-Puig AJ (2002) Isomer-dependent metabolic effects of conjugated linoleic acid: insights from molecular markers sterol regulatory element-binding protein-1c and LXR $\alpha$. Diabetes 51, 2037-2044.

Ryder JW, Portocarrero CP, Song XM, et al. (2001) Isomer-specific antidiabetic properties of conjugated linoleic acid. Improved glucose tolerance, skeletal muscle insulin action, and UCP-2 gene expression. Diabetes 50, 1149-1157.

Shulman GI (2000) Cellular mechanisms of insulin resistance. J Clin Invest 106, 171-176.

Sisk MB, Hausman DB, Martin RJ \& Azain MJ (2001) Dietary conjugated linoleic acid reduces adiposity in lean but not obese Zucker rats. J Nutr 131, 1668-1674.

Su ND, Liu XW, Kim MR, Jeong TS \& Sok DE (2003) Protective action of CLA against oxidative inactivation of paraoxonase 1, an antioxidant enzyme. Lipids 38, 615-622.

Taniguchi CM, Kondo T \& Sajan M (2005) Divergent regulation of hepatic glucose and lipid metabolism by phosphoinositide 3-kinase via Akt and PKC lambda/zeta. Cell Metab 3, 343-353. 
Tsuboyama-Kasaoka N, Takahashi M, Tanemura K, Kim HJ, Tange T, Okuyama H, Kasai M, Ikemoto S \& Ezaki O (2000) Conjugated linoleic acid supplementation reduces adipose tissue by apoptosis and develops lipodystrophy in mice. Diabetes 49, 1534-1542.

Tsuchida A, Yamauchi T, Ito Y, et al. (2004) Insulin/Foxo1 pathway regulates expression levels of adiponectin receptors and adiponectin sensitivity. J Biol Chem 279, 30817-30822.

Wallace DC (2001) A mitochondrial paradigm for degenerative diseases and ageing. Novartis Found Symp 235, 247-266.

Wallace TM, Levy JC \& Matthews DR (2004) Use and abuse of HOMA modeling. Diabetes Care 27, 1487-1495.

Wang Y \& Jones PJ (2004) Dietary conjugated linoleic acid and body composition. Am J Clin Nutr 79, 1153S-1158S.

Wargent E, Sennitt MV, Stocker C, et al. (2005) Prolonged treatment of genetically obese mice with conjugated linoleic acid improves glucose tolerance and lowers plasma insulin concentration: possible involvement of PPAR activation. Lipids Health Dis 4, 1-14.
Wharton DC \& Tzogaloff A (1967) Cytochrome oxidase from beef heart mitochondria. In Methods in Enzymology, vol. 10, pp. 245-247 [RW Estabrook and ME Pullman, editors]. New York: Academic Press.

Wisloff U, Najjar SM, Ellingsen O, et al. (2005) Cardiovascular risk factors emerge after artificial selection for low aerobic capacity. Science 307, 418-420.

Yamasaki M, Miyamoto Y, Chujo H, Nishiyama K, Tachibana H \& Yamada K (2005) Trans10, cis12-conjugated linoleic acid induces mitochondria-related apoptosis and lysosomal destabilization in rat hepatoma cells. Biochim Biophys Acta 1735, 176-184.

Yamauchi T, Kamon J, Ito Y, et al. (2003) Cloning of adiponectin receptors that mediate antidiabetic metabolic effects. Nature $\mathbf{4 2 3}$, $762-769$.

You M \& Crabb DW (2004) Recent advances in alcoholic liver disease II. Minireview: molecular mechanisms of alcoholic fatty liver. Am J Physiol 287, G1-G6. 